\title{
Fate of turkey spermatozoa after intrainfundibular and intramagnal inseminations
}

\author{
M. R. Bakst \\ U.S. Department of Agriculture, ARS, Avian Physiology Laboratory, Beltsville, Maryland 20705, \\ U.S.A.
}

\begin{abstract}
Summary. About $92 \%$ of the spermatozoa recovered after intrainfundibular inseminations of turkey hens were in the infundibulum and $6 \%$ in the magnal segments $24 \mathrm{~h}$ later. Of the spermatozoa recovered after intramagnal inseminations, about $67 \%$ were in the infundibulum, $26 \%$ in the magnal segments, and a total of about $8 \%$ in the isthmus, uterus, and vagina. It is suggested that spermatozoa in the infundibulum and magnum are not transported in significant numbers in an abovarian direction.
\end{abstract}

\section{Introduction}

Bakst (1981) showed that turkey spermatozoa were present in each segment of the oviduct immediately after oviposition, at 8-12 $\mathrm{h}$ and 18-22 $\mathrm{h}$ after oviposition with no one time after oviposition being associated with greater numbers of spermatozoa. It was concluded that, in the turkey, spermatozoa are released continuously or episodically from the uterovaginal junction sperm-host glands. An alternative explanation would be that spermatozoa are released at specific times of the ovulatory cycle and ascend variable distances between the uterovaginal junction and infundibulum during the course of the ovulatory cycle. An additional source of luminal spermatozoa in the turkey may be the infundibulum and proximal magnum which appear to serve as secondary sperm storage sites (Bakst, 1981). Whether spermatozoa in these segments are transported in an abovarian direction and thus contribute to the population of spermatozoa in the more distal segments is not known. Therefore, the objective of this study was to determine the efficacy of abovarian sperm transport after intrainfundibular and intramagnal inseminations.

\section{Materials and Methods}

Mature Small White turkey hens (20 in egg production for 4-9 weeks; 8 in production for 20-24 weeks; all about 33 weeks old at the start of egg production) were caged individually in a light-proof building with lights on from $01: 00$ to $15: 00 \mathrm{~h}$. Food and water were available continuously. Eggs laid were recorded hourly between 08:00 and 15:00 h. Semen was obtained from Large White turkeys and diluted at a rate of 1 part semen to 2 parts Beltsville Poultry Semen Extender (Sexton, 1977) and 25 hens were surgically inseminated 5-30 min after oviposition. Hens were anaesthetized locally with $2 \%$ lidocaine with epinephrine (A. J. Buck \& Son, Cockeysville, Maryland). An incision was made through the lateral abdominal wall and a short segment of the infundibulum or magnum was partly exteriorized and inseminated with about $137 \times 10^{6}$ spermatozoa.

Hens were killed by cervical dislocation $24 \mathrm{~h}$ after insemination. Oviducts were ligated at the base of the fimbria, $2 \mathrm{~cm}$ distal to the infundibulum-magnum junction, magnum-isthmus junction, isthmus-uterine junction, uterovaginal junction, and distal vagina. The magnum was further 
divided into 3 equal lengths (proximal, middle, and distal). Phosphate-buffered saline (PBS) was injected into each ligated segment until it was slightly distended. The volume of PBS injected (5-20 $\mathrm{ml}$ ) was determined by the length of the segment to be distended. The segment was gently rocked to ensure distribution of the PBS between the mucosal folds and the PBS washing was then collected into a $50 \mathrm{ml}$ test-tube. The PBS washing procedure was repeated. The pooled wash was centrifuged at $7700 \mathrm{~g}$ for $20 \mathrm{~min}$. The supernatant was carefully removed until 5-15 ml of wash remained with the pellet. The pellet was resuspended and spermatozoa were counted directly with a haemocytometer. Data were statistically analysed with Duncan's Multiple Range Test according to the General Linear Models Procedure (SAS) (Barr, Goodnight, Sall \& Helwig, 1976).

\section{Results}

The number of oviducal segments containing spermatozoa $24 \mathrm{~h}$ after intrainfundibular and intramagnal inseminations is shown in Table 1. Most of the spermatozoa were recovered from the infundibulum. More spermatozoa were recovered from the magnal segments when insemination had been into the magnum but for each segment of the oviduct there were no statistical differences in the percentages of spermatozoa recovered from hens inseminated into the infundibulum or magnum. The percentages of spermatozoa recovered from the same segment were not affected by the presence or absence of a uterine egg.

Table 1. Recovery of spermatozoa and numbers of segments containing spermatozoa after intrainfundibular and intramagnal inseminations

\begin{tabular}{lccc}
\hline & \multicolumn{2}{c}{$\%$ of total no. of spermatozoa recovered } \\
\cline { 2 - 4 } \multicolumn{1}{c}{$\begin{array}{c}\text { Oviducal } \\
\text { segment }\end{array}$} & Insemination site & Combined insemination \\
sites $(\mathrm{N}=25)$
\end{tabular}

Values in parentheses are the no. of segments containing spermatozoa.

ab Within each column values without a common superscript letter differ significantly $(P<0.05)$.

$* \mathrm{~N}=16$.

\section{Discussion}

Turkey spermatozoa are released from the uterovaginal junction sperm-host glands continuously or episodically and not necessarily in concert with oviposition and ovulation (Compton \& Van Krey, 1979; Bakst, 1981). The present study indicates that after intrainfundibular inseminations abovarian transport is negligible and $92.8 \%$ of the spermatozoa recovered are from the infundibulum. After intramagnal inseminations, $67 \cdot 1 \%$ of the spermatozoa are recovered from the infundibulum, about $25 \%$ from the magnal segments, and $<8 \%$ from segments distal to the magnum, again indicating that abovarian sperm transport is inefficient, at least in the infundibulum and magnum. Light microscopy revealed no spermatozoa in the uterovaginal junction sperm-host glands of hens after intrainfundibular inseminations and only a few partly 
filled glands in 2 of 8 hens after intramagnal inseminations. Van Krey, Ogasawara \& Lorenz (1966) also found few spermatozoa in the sperm-host glands after intramagnal inseminations.

Bakst (1981) noted large numbers of spermatozoa from vaginal washings 10-13 days after vaginal inseminations. It was suggested that these spermatozoa represented dead or aged spermatozoa released from the sperm-host glands, which are then transported in an abovarian direction and expelled through the vagina. Furthermore, Howarth (1971) noted that $57.6 \%$ of turkey spermatozoa which are vaginally inseminated are excreted within $15 \mathrm{~min}$ of insemination, and this also suggests abovarian transport.

Based on the above observations it is suggested that abovarian sperm transport anterior to the uterovaginal junction is inefficient and that spermatozoa residing in the infundibulum and proximal magnum do not contribute appreciably to the numbers of spermatozoa recovered from the more distal oviducal segments at various times after oviposition.

\section{References}

Bakst, M.R. (1981) Sperm recovery from oviducts of turkeys at known intervals after insemination and oviposition. J. Reprod. Fert. 62, 159-164.

Barr, A.J., Goodnight, J.H., Sall, J.P. \& Helwig, J.T. (1976) A Users Guide to SAS 76. Sparks Press, Raleigh, North Carolina.

Compton, M.M. \& Van Krey, H.P. (1979) Emptying of the uterovaginal sperm storage glands in the absence of ovulation and oviposition in the domestic hen. Poultry Sci. 58, 1696-1700.

Howarth, B., Jr (1971) Transport of spermatozoa in the reproductive tract of turkey hens. Poultry Sci. 50, 84 89.
Sexton, T.J. (1977) A new poultry semen extender. 1. Effect of extension on the fertility of chicken semen. Poultry Sci. 56, 1143-1146.

Van Krey, H.P., Ogasawara, F.X. \& Lorenz, F.W. (1966) Distribution of spermatozoa in the oviduct and fertility in domestic birds. IV. Fertility of spermatozoa from infundibular and uterovaginal glands. $J$. Reprod. Fert. 11, 257-262.

Received 25 June 1982 